\title{
ARTIGOS
}

\section{O CONCEITO DE CATEGORIA ONTOLÓGICA: UM NOVO ENFOQUE}

Lorenz B. Puntel *

RESUMO $O$ artigo oferece um novo enfoque do conceito de categoria ontológica. O ponto de partida é a afirmação de que as "ontologias da substância” baseiam-se na aceitação do Princípio da Composicionalidade Semântica, o qual se mostra ter implicações ontológicas inaceitáveis. Este artigo delineia uma nova semântica baseada no Princípio de Contextualidade Sentencial (ou Princípio do Contexto) e, em concordância com ele, uma nova ontologia. A partir desse princípio uma nova categoria semântica denominada "estado de coisas primário" ("primestado", de forma abreviada) é derivada, e é mostrado que sobre essa base é possível desenvolver a categoria ontológica fundamental e, em um sentido, única chamada "fato primário" ("primofato", de forma abreviada).

ABSTRACT The paper offers a new approach of the concept of ontological category. The starting point is the claim that the "substance ontologies" are based on the acceptance of the Semantic Compositionality Principle which is shown to have unacceptable ontological implications. The paper delineates a new semantics based on the Principle of Sentential Contextuality (or Context Principle) and, in accordance with it, a new ontology. From this principle a new semantic category dubbed "prime state of affairs" ("pristate" for short) is derived and it is shown that on this basis it is possible to work out the fundamental and, in one sense, unique ontological category called "prime fact" ("prifact" for short).

* Ludwig-Maximillian-Universität Miinchen 
Palavras-chave Metafísica, ontologia, categoria, semântica, princípio do contexto

\section{Preliminares}

Se queremos compreender o mundo, temos de reconhecer de início que ele é um todo altamente diferenciado e estruturado. Para esse fim vários filósofos, a começar por Aristóteles, fizeram uso do conceito de categoria. Este artigo não pretende apresentar um tratamento abrangente deste tópico, o que não seria possível neste espaço limitado. Em vez disso, pretende-se destacar a estrutura categorial da linguagem ordinária, que se revelará como sendo do tipo substância-propriedade. Argumenta-se-á que o conceito de substância, assim como o de uma propriedade abstrata ou universal, não é aceitável. Será feito um esforço no sentido de criar uma nova linguagem não comprometida com uma ontologia de substâncias e propriedades nem com qualquer tipo de dualismo entre o concreto e o abstrato, ou seja, entre items que são localizáveis no mundo espacial e/ou temporal e items que não o são.

Os filósofos concordam que as categorias são classificações fundamentais que determinam a maneira como pensamos e falamos sobre o mundo. Mas os filósofos discordam sobre como compreender a expressão "nossa maneira de pensar e falar sobre o mundo". Se tomarmos a cláusula "sobre o mundo" como tendo prioridade no plano da compreensão e da explanação, ou seja, como sendo a cláusula que determina como a outra cláusula "nossa maneira de pensar e falar" deve ser interpretada, então as categorias emergirão como tendo um estatuto ontológico, pois elas demarcarão diferentes tipos de items ou de entidades no mundo como constituindo as estruturas mais fundamentais do mundo. A categoria de substância, começando por Aristóteles, tem sido usualmente tomada como a categoria mais primária e mais fundamental.

Mas se entendermos "nossa maneira de pensar e falar sobre o mundo" na ordem inversa, assumindo a cláusula "nossa maneira de pensar e falar" como prioritária, então as categorias serão compreendidas como sendo os conceitos mais fundamentais dos quais dispomos na maneira mais geral de usar a linguagem. As categorias a priori de Kant dão prioridade à cláusula "nossa maneira de pensar", enquanto a filosofia analítica realizou seu linguistic turn, segundo o qual as categorias (freqüentemente chamadas de "esquemas conceituais") devem ser entendidas com base na prioridade de "nossa maneira de falar (sobre o mundo)". O objetivo do presente artigo é desenvolver uma teoria das "categorias ontológicas" na qual se demonstra que estes dois enfoques são dois lados da mesma medalha. 
Este ensaio divide-se em três seções. Na seção 1 serão apresentadas de forma esquemática - e submetidas a uma crítica concisa - as concepções mais importantes sobre categorias ontológicas presentes na filosofia contemporânea. O propósito da seção 1 é o de motivar o leitor a engajar-se na busca de um enfoque significativamente diferente deste tema. Na seção 2 este novo enfoque será elaborado sistematicamente. A estratégia geral pode ser delineada da seguinte forma: mostrar-se-á que a semântica pressuposta pelas "ontologias da substância” é composicional, i. e. que é uma semântica baseada no Princípio de Composicionalidade, como será demonstrado no fim da seção 1. Mostrar-se-á que este princípio tem implicações ontológicas inaceitáveis e que, portanto, deve ser rejeitado. Uma semântica baseada em um outro princípio, o Princípio de Contextualidade Sentencial (ou Princípio do Contexto), será então desenvolvida. O novo enfoque do conceito de categoria ontológica é o que resulta quando se desenvolve uma ontologia não-composicional. Será mostrado rapidamente, além disso, que as teorias contemporâneas que rejeitam a idéia de "substância" (as chamadas "teorias de feixe" — bundle theori$e s)$ apresentam a deficiência de não serem elaboradas na base de uma semântica conspícua. A seção 3 contém algumas observações finais.

\section{O estatuto altamente problemático da categoria de substância}

[1] O "conceito de substância" tem pelo menos três sentidos diferentes na filosofia contemporânea. De acordo com o primeiro sentido, a substância é um substratum no qual propriedades (e relações) subsistem ou ao qual inerem. Assim, o substratum é suposto ser uma entidade distinta de outra entidade, o atributo (i. e. propriedade e/ou relação), uma vez que o particular concreto ou indivíduo é considerado como sendo constituido por essas duas entidades. Esse substratum tem sido chamado de "particular puro" (bare particular), uma vez que ele é desprovido de todos os atributos. Existem vários problemas conceituais com essa concepção de particulares puros (cf. Denkel 2000 para uma boa apresentação desses problemas). Apresentarei o problema fundamental desse conceito conjuntamente com o problema fundamental relativo ao conceito do universal tomado como aquilo que um particular puro deve instanciar.

Uma segunda tendência rejeita a idéia de um particular puro, mas não a idéia de um sujeito. O conceito-chave introduzido pelos autores que favorecem esse enfoque, a fim de explanar o que eles entendem por substância ou particular concreto, é o de tipo (kind). M. Loux, por exemplo, afirma: 
Um particular concreto é, nesta visão, simplesmente uma instância do seu próprio tipo; e aristotélicos argumentam que ser uma instância de um tipo significa simplesmente exibir a forma de ser que é este tipo. Posto que a forma de ser é irredutivelmente unificada, as coisas que a exibem são elas mesmas entidades irredutivelmente unificadas, coisas que não podem ser construidas a partir de entidades ainda mais fundamentais. (Loux, 1998, p.121)

A idéia de sujeito, no entanto, não é completamente rejeitada por esses autores. Eles afirmam que as substâncias, ou particulares concretos, elas mesmos são os sujeitos de todos atributos associados a elas; mas eles se apressam em dizer que se deve distinguir entre atributos que são essenciais aos portadores e outros que são puramente acidentais. No segundo caso, o particular como portador de um atributo é compreendido como sujeito cuja essência ou cerne não inclui necessariamente este atributo; mas, de acordo com tais autores, no primeiro caso precisa ser reconhecida uma inclusão necessária de atributos, posto que a substância ou o particular concreto é também o sujeito de um tipo. M. Loux explica esta posição com um exemplo:

Sócrates é também um sujeito do tipo ser humano. É Sócrates, e não algum constituinte seu, que é a coisa que é humana. Mas o tipo ser humano é o que caracteriza Sócrates como o que ele é, de tal maneira que neste caso nosso sujeito não é algo com uma identidade independente do universal do qual ele é sujeito. Extraindo-se de Sócrates o ser homem não sobra nada que possa ser sujeito de algo. (Ibid. p.120)

Não há dúvida de que os defensores dessa visão fazem um esforço considerável a fim de eliminar a obscuridade da noção de substratum. Mas permanecem dúvidas fundamentais acerca de se ter realmente alcançado isto. $\mathrm{O}$ que significa dizer que um particular concreto é "simplesmente uma instância de seu próprio tipo"? Se o particular concreto é simplesmente identificado com seu próprio tipo, o conceito de instanciação deixa de ser elucidatório. Mas se se diz que "nosso sujeito não é algo com identidade independente do universal do qual ele é sujeito", então é difícil entender o que isto significa. Pois, como pode um item $x$ ser sujeito de um universal $\mathrm{U}$ se a identidade de $x$ não é independente de U? Talvez alguém possa dizer que neste caso se trata de um "caso-limite" do conceito de instanciação. Mas em filosofia casoslimites desta espécie são conceitos problemáticos. Eles são, em geral, indicadores da necessidade de introduzir outro "esquema conceitual" mais adequado para articular a intuição que se deseja expressar.

Um terceira tendência repudia o conceito de substratum (e sujeito) e introduz em seu lugar a característica de independência como "critério" da substância (cf. especialmente Hoffman e Rosenkrantz, 1994, cap. 4; Lowe 1998, cap. 6). Esse enfoque encontra-se em Descartes, Espinoza e outros. Ele afirma que a substância é independente por ser capaz de existir sozinha. Vá- 
rias compreensões divergentes do conceito de independência tem sido propostas. O problema central dessa concepção é que independência é uma condição apenas necessária, mas não suficiente, para ser uma substância. Ter independência é apenas um aspecto externo, e não a estrutura interna de uma substância.

[2] Teorias ontológicas que não aceitam a idéia tradicional de substância tratam particulares concretos (e todo tipo de entidades complexas) como feixes (bundles) de certos tipos de entidades. Tais teorias são em geral chamadas de teorias de feixe. No lugar da expressão "feixe", outras expressões também são usadas como, por exemplo, "configuração", "coleção", cluster e semelhantes. Usar-se-á, no presente artigo, a expressão "configuração" sempre que o autor se referir à sua própria posição. Mas existem teorias de feixe muito divergentes relativamente, em primeiro lugar, ao tipo de entidades consideradas constituintes de um feixe e, em segundo, ao sentido mais exato associado à expressão "feixe".

Três versões fundamentais devem ser mencionadas. A primeira versão, chamada de teoria de tropos (trope theory) ${ }^{1}$, é uma teoria radicalmente revisionária que não apenas rejeita a idéia de substratum e sujeito, mas também, e acima de tudo, põe em questão o conceito de universal. Filósofos que aceitam esta teoria admitem uma (nova) entidade ou categoria denominada de "tropo", e a caracterizam como um particular abstrato ou como uma propriedade (e relação) particularizada ou concretizada. De acordo com essa visão, tropos são os elementos fundamentais do ser, a partir dos quais todos os outros podem ser construidos. Mais precisamente, tropos são considerados a única categoria fundamental e a ontologia construída a partir de tropos é compreendida como uma ontologia monocategorial. Um particular concreto ou um indivíduo é explanado como um feixe de tropos: a entidade tradicionalmente chamada "universal" é reinterpretada como um coleção de tropos enfeixados por meio da relação de semelhança (cf. Williams 1953, Campbell 1990).

Essa concepção representa um novo e interessante desenvolvimento do conceito de categoria ontológica. Mas ela enfrenta várias dificuldades graves que tem sido apontadas por vários autores (veja, entre outros, Simons 1994, Daly 1994). Penso que a dificuldade mais saliente reside no fato de que essa teoria de tropos não conseguiu tornar claro como ela pode dispensar a relação de instanciação (cf. especialmente Daly 1994, pp.250-60), que é uma relação

1 Esta expressão foi introchzida por Williams, 1953, e é hoje commente usada na ontologia analítica. A expressão é derivada do grego trópoV segundo a significação de "modo, espécie". "Tropo" como categoria gramátical é o emprego de uma palavra em sentido figurado. 
que pressupõe o conceito de universal que a teoria de tropos pretende rejeitar. Essa dificuldade manifesta-se até mesmo na terminologia usada pelo teóricos de tropos, especialmente quando eles dizem, por exemplo, que tropos são "particulares abstratos", "propriedades (e relações) particularizadas" ou até mesmo "instâncias de propriedades (e relações)".

Essa dificuldade, por sua vez, tem suas raízes últimas no que se poderia tomar como sendo uma deficiência sistemática da teoria de tropos: embora essa teoria baseie-se em uma intuição de muito valor, ela carece inteiramente de uma semântica adequada para expressar essa intuição correta. A teoria de tropos mantém o tipo de semântica que é, em certo sentido, uma função da ontologia tradicional de substâncias e, em outro sentido, dá origem a uma nova ontologia, como será mostrado na seção 2. Teóricos de tropos simplesmente tomam a entidade "tropo" como o referente de expressões como "a posição de Napoleão" e semelhantes, mas eles não levantam a questão sobre qual tipo de ontologia é pressuposta ou implicada pelas outras expressões da linguagem ordinária ou natural. Os antigos conceitos de universais e particulares não são eliminados. A fim de estabelecer uma revisão genuína da ontologia de substância, os quadros lingüísticos ou semânticos pressupostos por ela precisam ser examinados em primeiro lugar. O novo enfoque a ser proposto neste artigo pode ser considerado como o resultado da tentativa de desenvolver sistematicamente o que o autor assume ser a intuição correta que subjaz à teoria de tropos. Mas esse novo enfoque introduz uma terminologia completamente nova derivada de uma nova semântica, rejeitando assim outras suposições básicas e outras afirmações feitas por teóricos dos tropos.

Uma segunda versão considera particulares concretos como feixes de qualidades unidos pela relação de co-presença. Finalmente, a terceira visão considera particulares concretos como feixes de universais imanentes, i. e., universais que, "em contraste com os universais platônicos, estão, tal como seus portadores, plenamente presentes no espaço e tempo". (O'Leary-Harthorne e Cover 1998, p. 205) ${ }^{2}$. Segundo essa versão, os universais assim compreendidos são os únicos constituentes fundamentais do mundo.

Deve-se também notar que alguns autores admitem tropos sem considerá-los como items ou elementos enfeixados no sentido da teoria de feixes. De acordo com esses autores, tropos, ao invés de universais, são combinados com um substratum a fim de constituir um particular concreto. Outra teoria, chamada teoria nuclear, desenvolve um enfoque de dois níveis: o primeiro

2 O' Leary-Hawthorne/Cover chamam a sua teoria "a teoria de feixes da substância" (ibid., p. 205) . Esses autores tomam simplesmente a expressão "substância" como sinônima de "particular concreto" ou "indivicual". Deve-se dizer, no mínimo, que esta terminologia é ambígüa. 
nível é compreendido como um feixe de tropos reunido que forma o cerne essencial, núcleo ou natureza essencial do particular concreto. $\mathrm{O}$ segundo nível é constituido de outros tropos não essenciais, que podem ser substituidos sem que o núcleo cesse de existir. Esse segundo nível é dependente do núcleo, na medida em que este é seu portador. "O núcleo é assim ele mesmo um feixe coeso que serve como substrato do feixe frouxo de tropos acidentais, garantindo assim sua coexistência." (Simons 1994, p.568). Essa versão não rejeita, portanto, inteiramente um substrato; ela apenas não aceita um substrato último.

[3] Segue agora a apresentação acima anunciada do problema fundamental das concepções de substância, tanto tradicionais como revisionárias. Todos os outros problemas são derivados de um problema fundamental, mas o espaço restrito não permite demonstrar esse ponto aqui. O problema fundamental reside no quadro semântico-ontológico pressuposto por todas as concepções de substância acima mencionadas. Trata-se do quadro característico das chamadas linguagens "naturais" ou "ordinárias" da tradição indo-européia. A sintaxe e a semântica dessas linguagens e a "ontologia da substância" são dois lados da mesma medalha. Mais exatamente: poder-se-ia falar do quadro semântico-ontológico elaborado e aceito pela grande maioria de filósofos que faz uso da linguagem natural e a teoretiza acerca dela. A linguagem natural "como tal", i. e. enquanto existindo independentemente da compreensão filosófica dela, deve ser diferenciada da linguagem natural usada, interpretada e teoretizada pelos filósofos. Além disso, é fato que existem várias visões filosóficas diferentes sobre a linguagem natural. Mas neste artigo a expressão "linguagem natural" será utilizada no sentido de "linguagem de predicados de primeira ordem". Essa formulação bem conhecida expressa um visão filosófica bem definida da linguagem natural.

A fim de analisar o problema fundamental em questão examinemos novamente as teorias de substância descritas acima de maneira breve. Devemos explicitar em primeiro lugar duas características do quadros semântico-ontológico subjacente a essas teorias. (i) Mesmo se, além da categoria de substância, outras categorias ontológicas forem introduzidas e aceitas (p. ex. evento, processo, e outras), uma estrutura semântico-ontológica mais fundamental é ainda pressuposta por todas essas teorias: a estrutura "diádica" sujeito-universaisl ou sujeito-atributos (atributos são propriedades e/ou relações). Essa estrutura categorial constitui o nível fundamental em relação a todas as outras categorias, sendo, portanto, pressuposta por essas outras categorias. Essa afirmação baseia-se no fato inegável de que as outras categorias ontológicas (como eventos, processos, etc.) são compreendidas como entidades que tem propriedades e estão em relação com outras entidades. Isso torna-se manifes- 
to pelo fato de serem essas categorias articuladas na estrutura sintático-semântica da linguagem de predicados de primeira ordem. Em sua interpretação padrão essa linguagem possui exatamente a estrutura semântica que corresponde à estrutura diádica de sujeitos-universais (atributos).

(ii) A semântica da linguagem de predicados de primeira ordem baseiase completa e fundamentalmente no Princípio de Composicionalidade, que, aplicado às sentenças, diz:

(PCPS) O significado (ou valor semântico) de uma sentença é uma função dos significados (ou valores semânticos) da seus componentes subsentenciais.

De acordo com esse princípio, admite-se uma independência, pelo menos relativa, dos valores semânticos dos componentes subsentenciais. Assim, o termo singular tem como seu referente próprio o denotatum; o predicado pelo menos em uma semântica realista - o seu próprio designatum, o atributo. O referente ou denotatum de um termo singular (e/ou nome próprio) é chamado de modo geral e não específico de "objeto" na filosofia analítica. Mas, como essa entidade é determinada através da atribuição de propriedades e relações, ela desempenha, sem dúvida, o papel da antiga categoria da substância, compreendida como sendo constituida por um sujeito (substratum) e universais.

O problema fundamental pode ser formulado agora como a questão posta pela predicação a nível da linguagem de predicados de primeira ordem. A forma mais fundamental e simples de predicação desse tipo é "Fa", isto é, a atibuição do atributo $F$ ao item $a$ (com quantificador: ( $\$ x(\mathrm{~F} x)$ ). $\mathrm{O}$ sujeito (substratum!) $a$ ou (o valor da variável ligada) $x$ é pressuposto de modo permanente e fundamental. Surge aqui o problema: uma tal entidade não é inteligível, posto que ex hypothesi, ou por suposição, ela tem de ser o item pressuposto para atribuir ou predicar quaisquer tipo de universais ou atributos, isto é, propriedades (e relações), bem como qualquer outro tipo de entidade que é atribuível a ela, por exemplo "estados de coisas" e/ou "fatos". Mas então se põe a questão de saber que é esta entidade pressuposta. Se todos os atributos (propriedades e relações) e todos os outros tipos de entidades como estados de coisas e/ou fatos são extraídos destes, parece não sobrar nada. Uma vez que a entidade em questão ( o "sujeito") é pressuposta em todo e qualquer caso de predicação, ela em si mesma não é determinada de forma alguma. Mas então ressurge a mesma questão: o que é esta entidade? Um tal entidade é ininteligível e deveria, então, ser rejeitada.

As tentativas de salvar a idéia de um tal sujeito fracassaram, pois se baseiam na suposição de que o "a" ou " $x$ ” é um sujeito que, em certo sentido, já está determinado. Mas, se for assim, em que sentido? Essa alegada "deter- 
minabilidade" do sujeito tem, ex hypothesi, de ser predicada desse próprio sujeito, mas, para possuir sentido, a predicação tem de pressupor um sujeito como uma entidade (ainda) não determinada. Essa suposição não responde a nada, pois é preciso esclarecer sob quais condições o caráter determinado a ser atribuido ao "a" ou " $x$ " adquire sentido. Em outras palavras: o que precisa ser esclarecido é a constituição ontológica deste sujeito.

Uma nova ontologia precisa ser elaborada para substituir essa ontologia substancialista. Isso requer a construção de uma nova semântica. A nova semântica precisa, ex hipothesi, evitar os problemas e dificuldades que resultam das doutrinas e pressuposições da semântica das linguagens naturais. Como podem ser construídas essa nova semântica e essa nova ontologia ontologia?

\section{Um novo enfoque: estado de coisas primário (Primestado ${ }^{36}$ ) como a única categoria ontológica no nível fundamental}

O que se segue é um esboço ligeiro dessa nova semântica e ontologia.

[1] A fim de evitar a estrutura sujeito-predicado das sentenças (atômicas), deve-se elaborar uma linguagem que seja isenta dos termos singulares (nomes próprios) e predicados, que são responsáveis pela ontologia substancialista das linguagens naturais indo-européias.

Essa idéia, porém, não é completamente desprovida de precedentes na literatura filosófica. Quine desenvolveu uma técnica interessante para eliminar termos singulares a fim de resolver o problema posto pelo fato de que muitos termos singulares (por exemplo, "Pegaso") não possuem referentes na vida real. Outros autores sustentam que predicados são completamente dispensáveis. Anteriomente a Quine, Russell já havia desenvolvido um procedimento lógico-semântico para clarificar as ambigüidades e perplexidades de fenômenos como as descrições definidas. Tais desenvolvimentos lógicosemânticos são o resultado da decisão de transformar significativamente a compreensão filosófica da linguagem natural. Claro que isso não significa que devemos parar de usar a linguagem natural no tocante à sua sintaxe, ou seja, não precisamos proibir a construção de sentenças do tipo sujeito-predicado. A transformação da linguagem proposta deve ser entendida, mais propriamente, com respeito à semântica e à ontologia dessa linguagem. Essa transformação envolve tradução e/ou reinterpretação.

3 Puntel cunha um neologismo ("pristate") como abreviação para "prime state of affairs". Optamos por traduzir esse neologismo por "primestado", apesar da ordem dos vocábulos na expressão em português "estado de coisas primário" nâo corresponder à ordem presente na expressão da lingua inglesa. [Nota do revisor da tradução]. 
Quine não compreende sua técnica de eliminação de termos singulares como sendo de importância semântica e ontológica. Pelo contrário, ele acentua que "os objetos permanecem como valores das variáveis apesar de os termos singulares terem sido postos de lado" (Quine 1960, p. 192, nota de rodapé 1). Nesse sentido, a abordagem perseguida neste artigo diverge radicalmente da posição de Quine. Explico melhor. Para Quine, a eliminação de termos singulares é apenas um instrumento lógico-semântico, cuja aplicação procura clarificar o problema colocado pelo fato de que alguns termos singulares, como "Pégaso" não possuírem referência real. A técnica consiste essencialmente em manobrar termos singulares para a posição padrão "=a", a qual, tomada como um todo, é um predicado ou termo geral. Mas termos gerais não são afetados pelos problemas que se colocam para os termos singulares. Vale citar a explicação detalhada de Quine:

\begin{abstract}
A equação " $\mathrm{x}=\mathrm{a}$ " é refraseada efetivamente como uma predicação " $\mathrm{x}=\mathrm{a}$ ", onde "= a" é o verbo, o "F" de "Fx". Ou então veja-se o seguinte. O que era nas palavras "x é Sócrates" e em símbolos "x = Sócrates" é agora em palavras ainda "x é Sócrates", mas o "é" deixa de ser tratado como um termo separado relativo "=". O "é" é tratado agora como cópula, que, como em "é mortal" ou "é um ser humano", serve apenas para dar ao termo geral a forma de um verbo e assim adequá-lo a uma posição predicativa. "Sócrates" se torna um termo geral que é verdadeiro quando aplicado somente a um objeto, mas geral por ser de agora em diante tratado como gramaticalmente admissível na posição predicativa e não em posições aptas para variáveis. Ele assume o papel do "F" de "Fa" e cessa de assumir o papel de "a". (Quine 1960, § 37, p.179)
\end{abstract}

Quine está concernido com a regulamentação da linguagem científica através dos meios da lógica de predicados padrão de primeira ordem, a qual ele considera ser "para bem ou mal, a forma adotada das teorias científicas" (Quine 1985, p.170). E ele pensa que a lógica de predicados "ganha a rigidez requerida através da reificação" (ibid.). Sentenças que não satisfazem as exigências da linguagem de predicados de primeira ordem são consideradas por Quine como sentenças sem contribução referencial. De fato, ele pensa que nós proferimos tais sentenças "sem pretender referir a algum objeto" (ibid., p.169). Ele mostra isto formulando a semântica e ontologia de uma "sentença observacional", como:

Um gato branco encara um cão e bufa.

A white cat is facing a dog and bristling.

É preferível usar aqui a versão inglesa do exemplo devido à engenhosidade linguística de Quine. Quine distingue dois "refraseamentos" dessa sentença. O primeiro é não-referencial: ele tem o efeito de "dissimular sua fun- 
ção referencial [da sentença]" (ibid.). De acordo com Quine, o refraseamento não-referencial equivale a dizer, na presença sensível de um gato, " it's catting [está gatando]" e a interpretar toda a sentença como:

I's catting whitely, bristlingsly, and dogwardly.

Se se afirma que o mundo é povoado por objetos, isto é, sujeitos/substâncias que tem propriedades e que estão em relações com outros objetos (sujeitos/subbstâncias), esse primeiro refraseamento é indubitavelmente não-referencial. Quine parece tomar como óbvio que o mundo é estruturado dessa maneira. Assim, sem a menor hesitação, ele adere ao que poderia ser chamado de "dogma da ontologia objetual ou substancialista". ${ }^{4}$

Em perfeito acordo com essa pré-concepção ontológica, Quine apresenta um segundo refraseamento que pretende articular a referência. Isso é obtido pelo procedimento de regimentação da linguagem; com isso obtem-se que a sentença é "adequada à lógica de predicados, a qual foi escolhida para moldar nossas teorias científicas" (ibid.):

( $x$ ( $x$ é um gato e $x$ é branco e $x$ está bufando e $x$ está na presença de um cão)

( $x$ ( $x$ is a cat and $x$ is white and $x$ is bristling and $x$ is dogward)

A técnica de Quine de eliminação de termos singulares mostra-se, assim, como sendo um mero truque lógico-semântico sem qualquer contribuição ontológica. Ao invés de considerar os "velhos" objetos como os denotados de termos singulares, eles são tomados como valores das variáveis quantificadas (de primeira ordem). Numa perspectiva ontológica nada mudou realmente: o truque lógico-semântico de Quine mantém intacta a velha ontologia "substancialista". É muito importante para o propósito do presente artigo clarificar bem essa questão, uma vez que a nova estrutura semântico-ontológica proposta se distancia de Quine exatamente nesse ponto. Em última análise, Quine pressupõe um $x$ como um sujeito. Sem essa pressuposição, a técnica, i. e. o truque lógico-semântico, de Quine não funcionaria. Em outras palavras: a razão pela qual Quine rejeita o refraseamento do tipo "está socratizando" é claro: esse refraseamento não contém um sujeito/substrato $x$. Isso mostra que Quine permanece preso à uma ontologia de objetos, de substâncias e, com isso, de sujeitos/substratos. ${ }^{5}$

4 A expressão 'objetual' é empregada por Quine para caracterizar uma leitura ou interpretação dos quantificadores (a "leitura dbjetual" por qposição à "leitura substitucional") .

5 Deve-se notar, todavia, que em outras passagens dos seus escritos Quine esboça uma dupla revisão ou reinterpretação da ontologia (cf. Quine 1981, cap. 1). Isto motiva a questão se (e como) tal revisão é compatível com a ontologia baseada na reificação. Mas esta questão não pode ser tratada neste ensaio. 
A fim de localizar, no interior da filosofia contemporânea, a abordagem desenvolvida neste artigo vale mencionar um outro filósofo. Em sua tentativa de desenvolver o que ele chama de "metafísica descritiva", P.F. Strawson tem em vista a fundação de uma teoria gramatical concebida em termos "da noção" ou "na base do esquema de substanciação + predicação complementar" (Strawson 1974, p. 135, 127). Ele pensa em um tipo de linguagem cujas sentenças são da forma sujeito-predicado. Mas, ao mesmo tempo, ele prefigura a possibilidade de uma linguagem "sem particulares", contendo apenas "sentenças que articulam somente localizações de traços fundamentais (featureplacing sentences)" como as seguintes: "está chovendo agora", "neve está a cair", "tem água aî". Tal linguagem elimina "particulares", ou seja, referentes de termos singulares como "sujeitos" de sentenças da forma sujeito-predicado.

O conceito de Strawson de "sentenças que articulam somente localizações de traços fundamentais ("feature-placing sentences")" é ambíguo em vários aspectos. Em primeiro lugar, como os exemplos acima o mostram, algumas das suas "sentenças que articulam somente localizações de traços fundamentais" [feature-placing sentences] contém "termos designativos de substâncias", como "neve", "água” e semelhantes. Mas tais sentenças possuem claramente a estrutura de sujeito-predicado. Em segundo lugar, Strawson tenta mostrar que as "sentenças que articulam somente localizações de traços fundamentais (feaure-placing sentences)" "não apresentam forte resistência de assimilação pela gramática substancialista" (ibid. p.136). A fim de realizar a proposta, ele propõe uma "expansão" do seu esquema de substanciação e predicação complementar através da introdução da "generalização do sujeito", cujo primeiro passo remove

\footnotetext{
a restrição das expressões de sujeito à função de substanciação de i.i. [isto é, indivíduo identificado] representando esse indivíduo como um caso especial de substanciação em geral. O passo seguinte consiste em remover a restrição de expressões de sujeito à função de substanciação representando esta função como um caso especial de uma função ainda mais geral - o que se podería chamar provisoriamente de sujeição-em-geral [subjection-in-general]. (Ibid. p.125)
}

Em terceiro lugar, ao fazer isso, Strawson nunca abandona a idéia fundamental de um sujeito e a idéia complementar de uma característica (um universal) que o determina. A sua "generalização do sujeito" gera particulares de acordo com o esquema substancialista, sendo que a única diferença em relação à posição tradicional é o fato de que o seu procedimento o conduz a uma distinção entre "particulares ordinários" e "particulares de um (certo) tipo".

Strawson nunca pôs em questão o conceito de sujeito. Ele ignora o que foi chamado acima (seção 1) de problema fundamental do esquema semântico-ontológico substancialista. 
[2] Se não prestarmos atenção apenas para questões e tópicos isolados, mas procedermos sistematicamente, teremos inevitavelmente de perguntar sobre qual/quais princípio(s) a nova semântica deve basear-se. Mas existe uma alternativa ao PCPS: o Princípio de Contextualidade Sentencial (PCTS) (freqüentemente chamado de Princípio do Contexto), que foi formulado pela primeira vez por Frege em 1884. Em uma das suas formulações, o princípio afirma:

(PCTS) "Somente no contexto de uma sentença as palavras tem um significado" (Frege 1884/1953: 62).

(Devido às ambigüidades da expressão "significado" é preferível falar de "valor semântico"). Mas Frege claramente mantém o PCTS também nos seus escritos posteriores. Existe uma grande controvérsia sobre o significado exato que Frege atribui ao PCTS e se ele continuou a mantê-lo em conexão com o PCPS. Muitos filósofos analíticos contemporâneos mantém o PCTS, usando algumas vezes outros nomes como "(Princípio do) Primado Semântico da Sentença” (Quine 1981, p.20). E, em geral, eles defendem que os dois princípios são perfeitamente compatíveis. Dessa forma, eles pressupõem o que poderia ser chamada a versão fraca do PCTS (a partir de aqui W-PCTS ["W" do inglês "weak"]). De acordo com a versão fraca, todo constituente sub-sentencial tem o seu próprio "significado" ou "valor semântico" somente na medida em que ele contribui para o significado ou valor semântico da sentença como um todo. Mas isto deixa toda a questão semântica e ontológica intocada: mudanças fundamentais na semântica e ontologia não são requeridas ou induzidas.

Para desenvolver um novo enfoque semântico e ontológico torna-.se necessário introduzir uma outra versão do PCTS, que poderia ser chamada de versão forte do PCTS (a partir de aqui S-PCTS ["S" do inglês "strong"]). Três aspectos caracterizam o S-PCTS:

[i] S-PCTS é incompatível com o PCPS.

[ii] Termos singulares e predicados são radicalmente eliminados de sentenças no tocante ao seu estatuto semântico. As sentenças que resultam dessa eliminação serão chamadas sentenças primárias. São sentenças da forma "verdeja", "chove", "leiteia", "mamãe" (tomada como abreviação de uma sentença), e semelhantes. No português filosófico poder-se-ia dizer adequadamente: "está F-zando", "F-zar" ou algo semelhante. (Mas "ser F" não o fará, uma vez que essa expressão designa uma propriedade (de acordo com uma visão realista das propriedades), uma entidade que requer uma outra entidade - um sujeito/substrato - da qual ela seja predicada).

[iii] Toda sentença primária descritiva, sintaticamente bem formada e semanticamente significativa de acordo com [i] e [ii], isto é, toda sentença 
primária, tem (ou expressa) um conteúdo informacional que pode ser designado de estado de coisas primário, ou, mais curto, primestado. Em um aspecto importante, essa entidade é o que, em uma lógica de predicados de primeira ordem, é, em geral, tomado como o designatum de um predicado. Apenas para tornar claro: os "antigos" predicados não estão contidos na linguagem reinterpretada como predicados, uma vez que predicados como tais foram eliminados. Mas a "função expressiva" exercida por essas expressões, que na linguagem da lógica de predicados de primeira ordem são consideradas "predicados", reaparece ou é mantida na "nova" linguagem na forma de uma sentença primária cuja forma geral é "está F-zando". Resumindo: o estado de coisas primário é o conteúdo informacional compreendido no uso da expressão "F" em sentenças primárias da forma "está F-zando".

Essa tentativa de substituir nossa linguagem ordinária ou natural por uma nova linguagem, dotada de uma semântica e ontologia superiores, pode parecer um exercício auto-contraditório, posto que emprega a linguagem ordinária que deveria ser superada na construção da linguagem substituta. É como se alguém tivesse de subir em uma escada e, então, a jogasse fora quando tivesse alcançado o topo. Mas isso pode realmente ser feito, como o evidencia a construção de linguagens científicas a partir da linguagem ordinária. (Até mesmo místicos fazem uso da linguagem ordinária para construir uma linguagem que pretende apresentar uma visão da realidade que é radicalmente diferente da realidade correspondente à linguagem natural). $\mathrm{O}$ primeiro estágio no projeto revisionário proposto neste artigo é apresentar argumentos, em linguagem ordinária, e em primeiro lugar a objeção acima denominada de problema central (cf. seção 1), a fim de motivar a construção de uma nova linguagem tornando-nos insatisfeitos com o comprometimento da linguagem ordinária com a ontologia de substância-atributo. $\mathrm{O}$ segundo estágio envolve a construção efetiva da linguagem nova e optimalizada. No que se segue será apresentado, na linguagem ordinária, um procedimento para construir, por meio de um processo de substração, uma sentença primária (e, consequentemente, um primestado), a partir de sentenças com a estrutura de sujeito-predicado.

Tomemos como ponto de partida a sentença ordinária com a estrutura de sujeito-predicado "S é F (ou Fs)". O conteúdo informacional expresso por essa sentença é que algum substância $S$ instancia o atributo abstrato ou universal ser $F$ (ou ser um F-zando). A seguir, subtrai-se o substrato $\mathrm{S}$ deste conteúdo informacional. O que sobra? Não pode ser o abstrato universal. A razão é que o universal está conceitualmente ligado ao conceito de substância no sentido de que um universal abstrato tem de admitir a possibilidade conceitual de o universal ser instanciado por uma substância, mesmo se não exis- 
tir realmente nenhuma substância. Assim, se o conceito de uma substãncia é impossível, como foi sustentado pela objeção central, então também o é o conceito de um universal abstrato. O que permanece é, portanto, não a propriedade abstrata de ser $F$ (ou ser um F-zando), mas um estado (ocorrência, evento ou processo) de F (ou F-zando), sem haver nenhuma substância que seja o sujeito de ou participante nesse estado ou evento.

Já foi mostrado que tanto os termos singulares (e nomes próprios) como os predicados propriamente ditos devem ser eliminados relativamente ao seu estatuto semântico. Mas não se requer que eles sejam eliminados da dimensão sintática da linguagem. Eles podem perfeitamente permanecer como items sintáticos, sob a condição que sejam reinterpretados semanticamente.

Existem duas maneiras de realizar e expressar tal reinterpretação. Uma maneira é tomar termos singulares (e nomes próprios) como abreviações de um grande número de sentenças primárias, mais exatamente, como abreviações de sentenças primárias que expressam primestados, os quais, como será mostrado, constituem configurações que costumamos chamar de "indivíduos" ("particulares concretos", "coisas", "objetos"). Predicados propriamente ditos (no sentido sintático), por sua vez, devem ser entendidos como abreviações de sentenças primárias que expressam um primestado (e eventualmente um primofato) pertencente a uma configuração de primestados. A outra maneira de formular a reinterpretação é introduzir uma sentença (não usual, artificial) que expressa um primestado complexo, isto é, uma configuração de primestados. A aplicação da forma profundamente modificada da técnica de Quine elaborada acima resultaria em uma sentença da forma: "está Socratizando filosoficamente". "Está Socratizando" é uma sentença primária complexa que expressa um primestado complexo (primofato). $\mathrm{O}$ advérbio "filosoficamente", por sua vez, deve ser interpretado como uma abreviação da sentença primária "está filosofando", que expressa o primestado singular correspondente.

Esse exemplo ilustra a reinterpretação semântica pretendida. A sentença "Sócrates é um filósofo" tem a forma sintática de sujeito-predicado. Uma das análises semi-formais possíveis da reinterpretação desta sentença, de acordo com a semântica e ontologia aqui esboçada, poderia ser essa:

Existe um $x$ de tal modo que $x$ é ("é" no sentido de "deve ser interpretado semantica e ontologicamente como") a configuração $S$ dos primestados $\mathrm{p}_{1}, \mathrm{p}_{2}, \ldots, \mathrm{p}_{\mathrm{r}}$ e existe um estado primário $\mathrm{p}_{\mathrm{i}}$ tal que $\mathrm{p}_{\mathrm{i}}$ é o estado primário de coisas expresso pela sentença primária ‘está filosofando' e $\mathrm{p}_{\mathrm{i}}$ é um componente constituinte de $\mathrm{S}$.

[3] Tendo alcançado este ponto, o enfoque proposto toma uma direção claramente ontológica. A entidade que aqui chamamos de primestado é o que 
uma sentença primária descritiva expressa. De acordo com a semântica aqui delineada, sentenças primárias são as únicas expressões lingüísticas enganchadas no (ou dotadas de uma conexão com o) mundo. Disto se segue que a dimensão ontológica dentro do quadro semântico-ontológico escolhido pode ser clarificada apenas a partir dessa base. Claro que a passagem da dimensão semântica para a ontológica precisa ser explicitamente considerada e esclarecida. Em uma semântica composicional, essa passagem é vista como tendo de ser realida em dois passos: primeiro como a relação de referência ao mundo, sendo essa relação tomada como uma característica semântica de termos singulares (e, dependendo de premissas ulteriores, de predicados); e segundo como a característica da verdade atribuida às sentenças compreendidas composicionalmente (e às proposições ou estados de coisas que elas expressam).

Mas, de acordo com a semântica não-composicional perseguida aqui, a única espécie de "referência" semântica (ao mundo) — pressupondo que se queira manter e usar a expressão 'referência' neste contexto - é uma característica unicamente das sentenças, mais exatamente, das sentenças primárias. E essa relação de referência das sentenças à dimensão ontológica também se revela como sendo também um direcionamento à dimensão ontológica que contém dois passos diferentes: primeiro, a sentença (primária) expressa um estado (primário) de coisas; segundo, o estado primário de coisas ocorre, isto é, é verdadeiro.

O passo decisivo em direção à ontologia é feito quando se esclarece o que significa dizer que um estado primário ocorre ou é verdadeiro. Trata-se aqui de um tema muito central que pertence à teoria da verdade, mas que não pode ser tratado adequadamente neste ensaio (cf. Puntel 1993 e 2001). Basta afirmar, sem apresentar argumentos, que a explanação mais consonante com a abordagem que vem sendo desenvolvida aqui consiste em dizer que um primestado verdadeiro ou que ocorre é simplesmente um fato primário (ou, mais breve, um primofato), sendo que o "é" aqui deve ser compreendido como o "é" de identidade. Essa é a tese central propugnada pela chamada Teoria da Verdade como Identidade (cf. Baldwin 1991, Dodd/Hornsby 1992; Puntel 1999; Puntel 2001). Frege formulou a conhecida questão "O que é um fato?" e sua resposta foi: "um fato é um pensamento que é verdadeiro" (Frege 1967, p.35). A identidade entre um estado de coisas (primário) e um fato pode ser vista como um caso limite da relação de correspondência (cf. Baldwin 1991, p.36; Brandom 1994, p.330).

Importa ressaltar aqui que a expressão "fato primário (primofato)" não é adequada porque tem quase exclusivamente conotações empíricas. Mas, de acordo com a concepção proposta aqui, essa categoria não deveria designar somente algo exclusivamente empírico, mas sim, ela penetra e trespassa to- 
dos os domínios do ser e do conhecimento, tanto empíricos quanto não-empíricos. Seria melhor introduzir outra expressão mais adequada. Ainda assim, é interessante notar que a expressão 'fato' na filosofia contemporânea é algumas vezes usada num sentido muito vasto e compreensivo para nomear algo semelhante a um fator. Esse é o caso quando se usa essa expressão em formulações como "fatos lógicos", "fatos matemáticos" e assim por diante. Claro que nestas formulações "fato" não designa nada de empírico. Porém, por falta de uma expressão mais adequada, será usada aqui a expressão "fato (primofato)".

[4] A estrutura semântica que acaba de ser esboçada conduz a uma importante conclusão: as únicas entidades (ou tipo de entidade) admissível são os primestados (e, levando em conta o estatuto completamente determinado dos primestados, os primofatos. Por razões de brevidade, em geral será usada somente a expressão "primestado"). Em outras palavras: estados primários não são apenas uma categoria ontológica entre outras, eles são a única categoria ontológica em um nível mais fundamental. Se a estrutura semântica delineada é aceita, a ontologia adequada é uma ontologia monocategorial (cf. Campbell 1990) $)^{6}$.

Mas seria errado inferir dessa afirmação que o mundo é algo como a totalidade de (um tipo de) primestados (primofatos) atômicos isolados e indiferenciados. De fato, a admissão de apenas uma única categoria ontológica no nível fundamental não impede que se reconheça três especificações centrais desta categoria. De acordo com o conceito de categoria ontológica elaborado neste ensaio, é possível conceber uma ontologia categorial altamente diferenciada e detalhada explanando todos os "dados ou fenômenos ontológicos" primeiramente como sendo (ou pertencendo a) sub-espécies ou tipos diferentes da categoria ontológica fundamental primestado. Em segundo lugar, através da redução de (certos) tipos de primestados a outros tipos de primestados. Em terceiro lugar, mostrando que primestados "simples" são membros de alguma configuração (de subespécies) primestados, sendo que a configuração, por sua vez, também é um primestado, mas neste caso um primestado complexo. Evidentemente, essa sistematização de uma ontologia categorial sobre a base da categoria fundamental de primestado representa uma enorme tarefa que não pode ser executada adequadamente neste artigo. Mas algumas pistas de como ela deveria ser concebida e elaborada podem ser

6 Para tornar mais precisa a concepção delineada algumas questões deveriam ser colocadas, especialmente a questão: quais são as condições de identidade para introduzir a entidade nomeada "primestado" (ou "primafato") ? O autor aceita o slogan de Quine de que não há entidade sem identidade e, então, isso - obriga a pronunciar critérios de identidade adequados para essa entidade em virtude dos quais ela possa ser sortida, reidentificada e contada. Limitações de espaço o impedem de fazê-lo neste artigo. 
apresentadas aqui. Voltamo-nos agora mais detalhadamente para cada uma dessas especificações.

[4.1] Com respeito à primeira especificação, deveríamos começar com a afirmação de que a categoria de primestado (primofato) é universal, sendo a única categoria no nível fundamental. Mas com isso se coloca a questão de como essa categoria pode fazer justiça à grande variedade de fenônemos ontológicos que as teorias de categorias examinadas na seção 1 procuram capturar. A maioria das categorias alistadas não podem ser integradas na concepção que está sendo desenvolvida aqui pela simples razão de que elas são o resultado direto de um esquema semântico-ontológico sem suficiente inteligibilidade. A esse grupo de categorias pertence, por exemplo, à parte a categoria de substância, a categoria de propriedade (relação). Mas o que fazer com "categorias" como eventos e processos? (Deve-se assinalar que, surpreendentemente, a maioria das "tabelas de categorias" propostas e defendidas na filosofia contemporânea nem mesmo menciona "processo"). Tais "categorias" não parecem ser simplesmente o resultado de uma estrutura linguística pré-fabricada. Elas parecem, mais propriamente, indicar algo ontológico que não combina bem com a estrutura lingüística natural cuja categoria central é a de substância.

Observemos primeiramente que não há primestados "universais" e/ou "particulares", se se compreende "particular" como "particularizado", pois isso pressuporia a aceitação de um universal. Essa é uma conseqüência direta da posição semântico-ontológica defendida neste artigo. Primestados são o que eles são "originalmente": eles são entidades singulares, não sendo o resultado de uma "instanciação", de uma "exemplificação", de uma "individuação", ou de algo de semelhante. Questões sobre "instanciação", "exemplificação" e "individuação" e outras semelhantes simplesmente não se colocam no esquema semântico-ontológico seguido aqui, posto que as pressuposições subjacentes a essas questões, a saber a aceitação de universais, não tem lugar no presente esquema. Se a expressão "(entidade) particular" é tomada no sentido de "entidade singular", então primestados podem ser chamados de "particulares primários".

No nível puramente descritivo podem ser facilmente distinguidos diferentes tipos de primestados. Por exemplo, as seguintes distinções entre tipos de primestados parecem impor-se por si mesmas: primestados abstratos e primestados concretos (mas existe um sério problema acerca da compreensão de um sentido exato - ou, ao menos, não-ambígüo - de "concreto" e "abstrato"); primestados uni-configuracionais: primestados que ocorrem em uma configuração de um modo tal que eles não conectam essa configuração com outras configurações (isto é, propriedades como reinterpretadas) e primestados pluri-configuracionais ou conectivos (isto é, relações como reinter- 
pretadas, por exemplo, primestados causais); primestados estáticos e dinâmicos (por exemplo, eventos, processos, etc.); e em um nível ontológico mais determinado: primestados constituidores do espaço e do tempo, primestados físicos, primestados biológicos, primestados mentais, primestados sociais; em um nível ontológico ainda mais problemático: primestados primários morais, primestados estéticos; além disso: primestados lingüísticos (primestados sintáticos, semânticos, pragmáticos); primestados ideais como conceitos, e todos os tipos de estruturas formais (regras), conjuntos, teorias, etc.

Se todas as entidades mencionadas forem consideradas tipos de uma única categoria de primestados, então surge a questão de saber se eles podem ser classificados de maneira sistemática. Esse é um problema distinto, uma tarefa imensa e extremamente árdua. Uma classificação sistemática de todos (e mesmo somente dos mais fundamentais) tipos de primestados somente pode ser atingida como como resultado de uma ontologia desenvolvida sistematicamente. Há muito trabalho teórico a ser realizado antes de se poder dizer que esta tarefa tenha sido cumprida, mesmo que só parcialmente. Mas para empreender esta tarefa de modo efetivo, é da maior importância considerar e clarificar duas questões ou tópicos centrais, que serão chamadas de questão reducionista e questão da configuração.

[4.2] A questão do reducionismo surge de considerações acerca diferentes níveis de análise, sendo que pelo menos dois níveis precisam ser reconhecidos, o nível da superfíciel e o nível da estrutura profunda. Análises do nível superficial são, em geral, puras descrições de um fenômeno, do significado de uma expressão, de um conceito e de coisas semelhantes tal como tais items apresentam-se ou aparecem sem (ou antes de) terem sido submetidos a uma análise exata da sua constituição interna. Análises da estrutura profunda, por outro lado, são o resultado de uma análise detalhada que vai além do nível da pura aparência ou auto-apresentação. Mas estrutura superficial e estrutura profunda não são necessariamente mutuamente excludentes. Elas apenas não devem ser confundidas uma com a outra, isto é, uma não pode ser tomada como sendo simplesmente idêntica à outra. $\mathrm{O}$ conceito de redução tem a função de evitar sistematicamente tal confusão, ou, para colocar em termos afirmativos: o conceito de redução articula a relação entre o nível da estrutura superficial e o nível da estrutura profunda. Para deixar claro: o nível da estrutura superficial tem claramente uma conotação negativa: isso significa que as entidades localizadas nesse nível precisam ser removidas ou radicalmente reinterpretadas.

Os tipos de primestados descritos acima situam-se no nível da estrutura superficial. Uma ontologia conspícua tem de articular os tipos de primestados perspícuos alcançados depois de aplicar o conceito e o processo de redu- 
ção aos tipos de primestados acima mencionados. Não seria exagero dizer que esta questão atravessa todas as áreas da filosofia. Ilustremos esse ponto com um exemplo. Poder-se-ia considerar o que acima foi chamado de primestados mentais como não sendo primestados genuinamente ontológicos reduzindo-os, digamos, a primestados puramente físicos. Na terminologia usada neste artigo, essa tese seria um fisicalismo redutivista (ou teoria da identidade) na área da Filosofia da Mente.

[4.3] A terceira especificação diz respeito ao tópico fundamental da configuração de primestados. Esse tópico precisa ser tratado considerando três questões.

[4.3.1] A primeira questão é motivada por uma leitura interna de uma forma especial de reducionismo: veladamente não são alguns, ou muitos, ou até mesmo a maioria dos primestados em realidade não meras entidades simples, isto é, primestados em sentido absolutamente estrito, mas sim entidades complexas, isto é, configurações (feixes) de primestados? Essa questão é extremamente importante. Se colocarmos as questões terminológicas de lado por um momento, exemplos de reducionismos de entidades aparentemente simples a entidades compostas ou complexas - configurações de alguma espécie - são abundantes na história da filosofia e da ciência. O exemplo talvez mais famoso seja a história do conceito de átomo. Como a palavra conota, um átomo é uma entidade indivisível (simples), mas o progresso da ciência revelou que o que a ciência por muito tempo considerou ser um átomo no sentido estrito é, em realidade, uma entidade composta. (Não obstante, a ciência e a filosofia continuam a usar a expressão "átomo" para designar o tipo de entidade composta originalmente tomada por um "átomo" propriamente dito). Durante vários séculos, a água foi considerada um "elemento", uma entidade simples, não- composta. Hoje ninguém duvida que a água seja $\mathrm{H}_{2} \mathrm{O}$ : uma molécula de água é uma configuração de dois átomos de hidrogênio e um átomo de oxigênio, sendo que cada um dos átomos de hidrogênio é ligado quimicamente ao átomo de oxigênio.

É difícil negar que algumas das entidades mencionadas acima como sendo primestados no nível da estrutura superficial, especialmente eventos e processos, são, em realidade, isto é, quando considerados no nível da estrutura profunda, não entidades simples, mas entidades muito complexas. Em nossa terminologia: configurações de muitos tipos significativamente distintos de primestados. Tome-se como exemplo de um evento a morte de um cavalo e como exemplo de um processo a evolução de um ser humano. Tais exemplos mostram como morte e evolução são entidades altamente complexas ou compostas. Em outras palavras, essas entidades são configurações de muitos primestados diversificados. 
[4.3.2] Essas considerações dão origem a uma segunda questão concernente à idéia de configuração: como devem ser caracterizados esse conceito e essa entidade?

Esse problema é notório para todas as versões da assim chamada teoria de feixes. Apesar das dificuldades colocadas para as teorias opostas à teoria de feixes, muitos filósofos evitam assumir uma versão da teoria de feixes porque eles não vêem como conceber o conceito de um feixe ou configuração de maneira que nossas intuições concernentes a indivíduos, especialmente pessoas humanas, sejam captadas de modo adequado. Por outro lado, os argumentos contra todas as teorias que admitem a substância como categoria fundamental parecem carregar tanto peso que é preferível assumir alguma versão da teoria de feixes ou configurações, mesmo que o conceito de feixe/ configuração ainda não tenha sido satisfatoriamente clarificado.

Observemos apenas nesse contexto que vários filósofos têm procurado esclarecer o conceito de feixe/configuração, dentre outras coisas, recorrendo a instrumentos formais como a mereologia, a teoria de conjuntos e até mesmo a topologia matemática, muitas vezes combinando estes recursos a fim de explanar esse conceito (veja, por exemplo, Simons 1987 e 1994, Bacon 1995 , Mormann 1995). Mas deve-se notar que todas estas tentativas padecem do fato de permanecer na obscuridade o caráter das entidades que compõem uma configuração. Alguns autores admitem universais, outros rejeitam universais e introduzem, em seu lugar, "tropos" (particulares abstratos), ainda outros falam simplesmente de "qualidades", e assim por diante. Uma vez que o conceito de feixe ou configuração torna explícita a conexão entre os items no feixe ou configuração, é óbvio que a clarificação do conceito depende fundamentalmente da questão acerca dos tipos de entidades a serem admitidos. A principal motivação para desenvolver o novo enfoque neste ensaio reside precisamente na convicção de que o primeiro passo sistemático a ser feito por uma ontologia conspícua tem de ser a clarificação sistemática da questão acerca do tipo de entidade que deve ser admitido.

[4.3.3] Finalmente, a terceira questão a se colocar no tocante ao conceito de configuração é essa: qual o lugar do conceito de um feixe/configuração em uma ontologia sistemática? Essa questão surge do fato de que até este momento um tópico central ainda não foi tratado (e mesmo nem foi mencionado).

Em primeiro lugar, a exposição até agora apresentada cria a impressão de que a concepção examinada deveria ser considerada uma espécie de atomismo semântico e ontológico. A estrutura categorial do mundo a que se chegou parece, no mínimo, estar no espírito do atomismo lógico, desde que, no lugar de "lógico", se diga "semântico-ontológico". Não se pretendeu afir- 
mar que o mundo é constituído a partir de entidades pertencentes somente a uma única categoria ontológica chamada primestados (primofatos), mesmo se essa categoria é compreendida como sendo diversificada em muitos tipos diferentes? Não são estes primestados simples e tipos de primestados os átomos últimos a partir dos quais o mundo é estruturado? E não é uma consequência inelutável dessa base "atomística" que as conexões entre primestados possam ser conexões puramente externas (não-essenciais) de um tipo claramente secundário ou derivado? Esse último ponto concerne tanto às conexões entre os primestados simples numericamente distintos que constituem um único feixe (ou configuração) complexo quanto às conexões entre feixes (ou configurações) distintos. Isso não parece ser uma forma perfeita de um atomismo ontológico baseado em primestados (primofatos)?

A resposta é: não necessariamente. A impressão de que a nova concepção proposta implica alguma versão de atomismo ontológico deve-se ao fato de que a apresentação do quadro semântico-ontológico teve de ser restringida à elaboração de apenas alguns aspectos da concepção semântico-ontológica tencionada. E não se pode negar que, com base somente nesses poucos aspectos, uma versão de atomismo ontológico não pode ser excluída de modo peremptório. Mas de uma elaboração integral do quadro semântico-ontológico parcialmente esboçado acima resulta uma visão completamente diferente: uma visão marcadamente holística. Essa afirmação será esclarecida e justificada na parte final deste ensaio.

Primeiramente, uma configuração de primestados pertence à mesma categoria semântico-ontológica que tem sido chamada de "primestado" ("primofato"): uma configuração de de primestados é também um primestado, mas um primestado complexo. Esse ponto é exatamente análogo ao bem conhecido fato da lógica sentencial (ou lógica proposicional) de que uma conjunção de sentenças (ou proposições) é também uma sentença (proposição), mas uma sentença (proposição) complexa.

A expressão "primário" foi introduzida para caracterizar o novo sentido específico que tem de ser atribuído às expressões "sentença" e "estado de coisas". "Primário" não significa "atômico" , "simples" (isto é, não-complexo). "Primário" significa, mais propriamente, que nenhum "sujeito" (termo singular, nome próprio, e assemelhados) ocorre como um fator semanticamente relevante na sentança e que, consequentemente, o estado de coisas expresso por uma tal sentença não contém nada como um "sujeito", uma "substância" no sentido de uma entidade $x$ possuindo propriedades $\mathrm{F}$ e/ou mantendo relações com outras substâncias (frequentemente chamadas "objetos"). Colocando em termos afirmativos: "primário" é usado para caracterizar sentenças/estados de coisas da forma "está F-zando". Desse significado 
atribuído a "primário" segue-se que sentenças primárias e estados primários de coisas ("primestados" e "primofatos") podem ser primestados/sentenças primárias simples (atômicos, não-complexos) assim como configurações desses, isto é, sentenças primárias complexas e primestados (primofatos) complexos.

Sem desenvolver detalhadamente uma ontologia sistemática é difícil, ou talvez mesmo impossível, dar exemplos de primestados absoluta e irredutivelmente simples ("atômicos" em sentido estrito). Tal como foi feito acima, pode-se dar exemplos de primestados "simples" relativamente a um quadro semântico-ontológico dado (aceito ou utilizado). Por exemplo, dentro do quadro lingüístico natural, um ponto colorido seria considerado como um primestado simples (atômico), mas as coisas mudam completamente se localizamos um "ponto colorido" no interior de um quadro científico.

A metafísica tradicional cristã (pré-kantiana) sustentava que a mente ou alma é uma entidade imaterial (espiritual) simples. Suponhamos agora que um filósofo que aceita o quadro ontológico proposto no presente ensaio está preparado para endossar a afirmação de que a mente (o espírito) é uma entidade imaterial. Ele teria, então, de dizer que a mente não é uma substância, mas um primestado (primofato). Teria ele de dizer além disso que a mente é um primestado simples (não-complexo)? Não é difícil mostrar que o conceito de simplicidade pressuposto pela metafísica tradicional revela-se ser, nesse caso, profundamente problemático. Com efeito, a metafísica cristã pré-kantiana havia assumido que a alma ou mente é dotada de duas "faculdades essenciais": o intelecto e a vontade. Ora, como conciliar essa tese com a afirmação de que a mente é uma entidade simples? Fica evidente aqui que essa metafísica tinha um conceito muito superficial e inadequado de simplicidade: esse conceito era definido de modo exclusivamente negativo e parcial, a saber como indivisibilidade, sendo que divisibilidade era considerada uma característica de entidades com partes ou componentes materiais. Mas componentes materiais não são de modo nenhum a única espécie de "componentes" que podem ser concebidos. Consequentemente, se se afirma que a mente é uma entidade imaterial e se, em consonância com a concepção esboçada neste ensaio, caracteriza-se a mente como sendo um primestado (primofato), não se segue que a mente seja um primestado simples; ao contrário, a mente é uma configuração de um certo tipo de primestados (imateriais).

Não é difícil dar exemplos quanto à outra espécie de primestados, os primestados complexos, isto é, as configurações de primestados. Um exemplo eloquente foi examinado acima: "Sócrates é um filósofo". O nome "Sócrates" pode ser tomado como uma abreviação de um grande número de sentenças primárias, cada uma das quais expressando um primestado primário. 
Os primestados primários, considerados conjuntamente, constituem uma primestado complexo, uma configuração de primestados. Ou pode-se introduzir uma nova sentença, uma sentença artificial: "está Socratizando filosoficamente" (ver acima [2]). Essa segunda maneria de expressar a reinterpretação é mais congenial à concepção defendida neste ensaio, dado que ela articula explicitamente a configuração como um todo.

Tendo notado que primestados podem ser simples ou complexos, podemos agora tentar dar uma resposta à terceira questão mencionada acima, quer dizer, a questão de saber que lugar sistemático deveria ser atribuido a cada um desses tipos de primestados, especialmente aos primestados complexos, isto é, às configurações de primestados. Um tratamento adequado dessa questão vai muito além do que pode ser tratado neste ensaio. Falando em termos mais exatos, trata-se da seguinte questão: devem os primestados complexos ser considerados como sendo constituídos a partir de primestados simples ao modo como o atomismo lógico (e ontológico) tradicional caracterizava entidades complexas de todo tipo e em todos os domínios? Ou deveriam primestados complexos, isto é, configurações de primestados, serem vistos em uma perspectiva holística como sendo os "pontos" ou "lugares" sistemáticos propriamente ditos que constituem as conexões entre os primestados?

Uma consideração final será apresentada para mostrar que uma concepção holística deveria ser favorecida. O enfoque proposto para uma nova concepção do conceito de categoria ontológica apoia-se fundamentalmente em considerações de caráter semântico. Mas como deveria ser concebida uma semântica sistemática, uma filosofia sistemática da linguagem? A perspectiva holística parece ser essencial para esse projeto. Foi mostrado que as sentenças são as unidades semânticas centrais de acordo com a Versão Forte do Princípio de Contextualidade Sentencial. Mas sentenças não ocorrem isoladamente. Elas constituem o todo que chamamos de linguagem. Parece que essa intuição somente pode ser levada a sério se se introduz um princípio ulterior, mais compreensivo, o Princípio da Contextualidade Holística:

(PCTH) Somente no contexto da linguagem como um todo as sentenças adquirem um valor semânticos.

Mas, se a concepção atomística da linguagem é rejeitada, então isso tem consequências importantes para a ontologia derivada da semântica não-holística. A idéia de configuração revelar-se-ia como absolutamente central tanto na área da semântica quanto na área da ontologia. Mas esse tópico não pode ser desenvolvido mais detalhadamente neste ensaio. 


\section{Observaçôes finais}

A finalidade deste ensaio foi a elaboração do conceito de categoria ontológica a partir de um novo enfoque. As posições contemporâneas mais proeminentes nessa área foram sucintamente apresentadas e submetidas a uma crítica concisa. O novo enfoque emergiu daquilo que a crítica revelou: uma nova ontologia deveria ser considerada como o resultado de se levar a sério a tese de que semântica e ontologia são dois lados da mesma moeda. De acordo com isso, para evitar as dificuldades que afetam a ontologia da substância e suas diversas formas, a semântica subjacente à ontologia da substância, que se baseia no Princípio de Composicionalidade Semântica deveria ser rejeitada em favor de uma nova semântica baseada no Princípio de Contextualidade Semântica. Essa nova semântica produz uma nova ontologia cuja única categoria no nível fundamental é a categoria de estado de coisas primário (primestado) ou, no nível ontológico próprio, a categoria de fato primário (primofato).

Esse resultado representa somente o primeiro passo na elaboração de uma nova ontologia compreensiva. Na última parte do ensaio foram dadas algumas indicações acerca de algumas das mais importantes questões com as quais essa nova ontologia deverá enfrentar. Ainda assim, a concepção proposta permanece ainda muito vaga e abstrata. Muitos tópicos centrais nem chegaram a ser mencionados, por exemplo o tópico central do espaço e do tempo. Resta ainda fazer uma grande parte de trabalho filosófico diversificado. Mas, sem haver primeiramente elaborado os fundamentos, uma nova ontologia não é digna de ser desenvolvida, pois ela repousaria sobre pressuposições básicas não-esclarecidas.

O leitor que simpatiza com o novo enfoque delineado neste artigo está convocado a consultar a literatura sobre a teoria de tropos (cf. especialmente Campbell 1990, Bacon 1995, Mormann 1995). Com respeito à perspectiva geral e a muitos tópicos específicos importantes, essa ontologia aproxima-se muito da nova ontologia desenvolvida no presente ensaio.

\section{BIBLIOGRAFIA}

Bacon, J., 1995, Universals and Property Instances. The Alphabet of Being. Oxford: Blackwell.

Baldwin, Th., 1991, “The Identity Theory of Truth". Mind 100, pp. 35-52.

Brandom, R. B., 1994, Making It Explicit. Reasoning, Representing, and Discursive Commitment. Cambridge, Ma., nd London: Harvard University Press.

Campbell, K., 1990, Abstract Particulars. Oxford: Blackwell.

Daly, Ch., 1994, "Tropes". Proceedings of the Aristotelian Society. New Series, 94, pp. 253-261. 
Denkel, A., 2000, “The Refutation of Substrata". Philosophy and Phenomenological Research. LXI, pp. 431-439.

Frege, G., 1884/1953, The Foundations of Arithmetic [Die Grundalgen der Arithmetik, 1884]. Transl. J. L. Austin, 2nd edition. Oxford: Blackwell.

Frege, G., 1967, "The Thought”, in P. Strawson (editor), Philosophical Logic. Oxford: Oxford University Press, pp. 17-38.

Hoffman, J., and Rosenkrantz, G. S., 1994, Substance Among Other Categories. Cambridge: Cambridge University Press.

Loux, M. J., 1998, Metaphysics. A Contemporary Introduction. London and New York: Routledge.

Lowe, E. J., 1998, The Possibility of Metaphysics. Substance, Identity, and Time. Oxford: Clarendon Press.

Mormann, Th., 1995, “Trope Sheaves. A Topological Ontology of Tropes”. Logic and Logical Philosophy 3, pp. 129-150.

O'Leary-Hawthorne, J., and Cover, J. A., 1998, “A World of Universals”. Philosophical Studies 91, pp. 205-219.

Puntel, L. B., 1999, “The 'Identity Theory of Truth': Semanctic and Ontological Aspects". In: Rationality, Realism, Revision. Editado por J. Nida-Rümelin. Berlin New York: de Gruyter, pp. 351-358.

Puntel, L. B., 2001, "Truth, Sentential Non-Compositionality, and Ontology", Synthese 126, pp. 221-259.

Quine, W. V. O., 1960, Word and Object. Crambridge, Mass.: The M.I.T. Press

Quine, W. V. O., 1981, Theories and Things. Cambridge, Mass.: Harvard University Press.

Quine, W. V. O., 1985, “Events and Reification”. In E. LePore e B. P. McLaughlin (eds.), Actions and Events. Perspectives on the Philosophy of Donald Davidson. Oxford: Blackwell, pp. 162-171.

Simons, P., 1994, "Particulars in Particular Clothing: Three Trope Theories of Substance". Philosophy and Phenomenological Research LIV, pp. 553-575.

Strawson, P. F., 1974, Subject and Predicate in Logic and Grammar. London: Methuen.

Williams, D. C., 1953, “On The Elements of Being”. Review of Metaphysics 7, pp. 13-18, 171-92.

E-mail: puntel@compuserve.com

Tradução:

Guido Imaguire - UFC

Revisão e versão final da tradução:

Edgar Marques - UFMG 
